\title{
A EXPERIÊNCIA DE REFORMA CURRICULAR DO CURSO DE DESIGN GRÁFICO
} DA UEL

The experience of curriculum reform of Graphic Design Course of UEL

\author{
SAMPAIO, Cláudio Pereira I Mestre \\ Universidade Estadual de Londrina - UEL \\ claudiopereira@uel.br
}

\section{LOPES, Camila Santos Doubek I Mestre}

Universidade Estadual de Londrina - UEL

uel.camila@gmail.com

\section{ZERBETTO, Cristiane Affonso de Almeida I DOUTORA}

Universidade Estadual de Londrina - UEL

cra@uel.br

\section{Resumo}

Com o vigoramento das Diretrizes Curriculares Nacionais (DCN), de 2004, os cursos de Graduação em Design possuem vasta liberdade na criação de seus currículos, gerando diversas linhas de formação curricular. Este artigo descreve a experiência de reforma curricular do Curso de Design Gráfico da UEL, em 2013 e 2014. Como resultado, foram desenvolvidas duas propostas, uma com base em módulos por projetos, e outra mais moderada, num modelo que compõe o desenvolvimento de projetos como elementos integradores dos conteúdos estudados, os quais se mantêm sob a forma de disciplinas.

Palavras Chave: Reforma curricular; Design Gráfico; Ensino e aprendizagem.

\section{Abstract}

Today, with the National Curriculum Guidelines (DCN), 2004 courses Undergraduate Design have extensive freedom in creating their resumes, generating several lines of curricular training. This article describes the experience of curriculum reform Course of Graphic Design at UEL in 2013 and 2014. As a result, it was developed two proposals, one based on modules for projects, and other more moderate, a model that consists of the development projects were developed and integrating elements of the contents studied, which remain as subjects.

Keywords: curricular reform; Graphic design; Teaching and learning. 


\section{INTRODUC̣̃̃O}

\section{O ensino de design no Brasil}

Segundo Couto (2008), o início do aprendizado de design no Brasil ocorreu em 1950, com a iniciativa que durou apenas dois anos, de Lina Bo Bardi e Giancarlo Pallanti, a partir de um curso regular de design no IAC do Museu de Arte de São Paulo. Já em 1963, de forma duradoura, foi criada a criação da ESDI - Escola Superior de Desenho Industrial, na cidade do Rio de Janeiro.

O currículo então empregado pela ESDI se tornou paradigma para o ensino de design no Brasil. A constante visita de docentes da Hfg - Hochschule für Gestaltung como Tomás Maldonado e Max Bill marcaram a influência da pedagogia Bauhausiana na ESDI. O currículo da ESDI, apesar de inovador, recebeu algumas críticas pela falta de sintonia com o grau de desenvolvimento da indústria nacional.

Em 1968, por questões políticas e considerando o contexto industrial, a ESDI parou para repensar o seu currículo, que era dividido em matérias básicas e profissionais para o curso de Desenho Industrial.

Em 1978, o CFE - Conselho Federal de Educação criou uma comissão de especialistas para elaborar um novo currículo para a área, o chamado currículo mínimo, pois neste período já existiam 16 cursos de design no Brasil com estruturas curriculares díspares. Nesta ocasião ocorreu a separação do curso em Projeto do Produto e Programação Visual.

No currículo mínimo, matérias são desdobradas em disciplinas isoladas criando uma separação artificial do saber. Tal fato tem gerado consequências negativas na formação dos alunos, que, em sua maioria, não consegue sintetizar, unir todo esse conhecimento a ponto de ter uma visão sistêmica do curso.

Em 1997, o I Fórum de Dirigentes de Cursos de Desenho Industrial, em Recife, apontou para uma urgente reforma curricular.

São vários os problemas ligados à má formação do designer na atualidade, pode-se citar formação inadequada dos docentes, ensino fundamental precário, pouca bibliografia nacional especializada, mas a questão mais problemática, sem dúvida, é o currículo mínimo vigente.

Quatro anos após a criação da CEEARTES, Comissão de Especialistas em Ensino das Artes e do Design, que representava associações e instituições das áreas de artes plásticas, música, dança, teatro, educação artística e design, 
- CEEDesign assumiu integralmente a tarefa de configuração das diretrizes curriculares para esta área específica. O CEEDesign foi gerado através da portaria de 10 de março de 1998.

A CEEDesign concentrou esforços na formulação das Diretrizes Curriculares para Bacharelados em Design, elaboração de instrumento para avaliação e reconhecimento de cursos de Graduação em Design, assim como ampliou o cadastro de avaliadores de curso.

Quanto às novas diretrizes, estabelecidas em 1999, foi estabelecido que:

- o curso de Bacharelado em Desenho Industrial passaria a se chamar "Bacharelado em Design", seguido do nome da habilitação ou ênfase conforme cada caso.

- a criação de um "Núcleo Básico Comum de Conteúdos", dividido em quatro blocos: (i) fundamentação, que compreende o estudo da história e das teorias do Design; (ii) planejamento e configuração, com o estudo de métodos de projetos; (iii) sistemas de utilização, englobando o estudo das relações homem-objeto, e (iv) sistemas de produção, englobando o estudo de materiais e processos.

Tais blocos deveriam ser trabalhados não como blocos de conteúdos fechados, mas de forma orgânica e integrada. Cada bloco deveria estabelecer as disciplinas pertinentes.

A carga horária mínima deveria ficar em torno de 3.200 horas, sendo que $50 \%$ desta carga horária deveria ser preenchida com conhecimentos relacionados à habilitação do curso e atividades extra disciplinares.

\section{As diretrizes curriculares nacionais}

Por intermédio de pareceres CES/CNE 0146/2002, 67/2003 e 0195/2003 da Câmara de Educação Superior do Conselho Nacional de Educação, ficou estabelecido que as novas Diretrizes Curriculares Nacionais deveriam servir de base para a composição dos currículos. Vale salientar que as diretrizes são de caráter obrigatório. O principal objetivo destas é endossar aos cursos de Design vasta liberdade na atribuição de cargas horárias a serem cumpridas para a conclusão do curso, isto é, a DCN marcaram a autonomia dos espaços acadêmicos. Antes, com o Currículo Mínimo, o Conselho Federal de Educação - CFE estabelecia os componentes obrigatórios, inclusive o detalhamento do conteúdo programático. Doravante cada Instituição de Ensino Superior é 
responsável pela qualidade de seu currículo e curso.

Os principais pontos abordados pelas diretrizes são: organização do curso, projeto pedagógico, organização curricular, atividades complementares, acompanhamento e avaliação e monografia/projetos/trabalhos de conclusão de curso.

Adicionalmente a Câmera de Educação Superior pontua alguns princípios fundamentais:

- Total liberdade das Instituições quanto à determinação das disciplinas e cargas horárias;

- Furtar-se do prolongamento desnecessário da duração dos cursos;

- Salvar-se do estabelecimento de conteúdos específicos contendo cargas horárias pré-determinadas.

Em termos práticos, foram definidos

... níveis de abordagem, perfil do formando, competências e habilidades, habilitações, conteúdos ou tópicos de estudo, duração dos cursos, atividades práticas e complementares, aproveitamento de atividades extracurriculares, interação com a avaliação institucional como eixo balizador para - credenciamento e avaliação da Instituição, para a autorização e reconhecimento de cursos, bem como suas renovações, adotados indicadores de qualidade, sem prejuízo de outros aportes considerados necessários (COUTO, 2008, p. 45).

- As aulas não poderão superar 50\% da carga horária total do curso;

- Encorajar técnicas de estudos independentes e práticas profissionais julgadas importantes para a área;

- Avigorar a interrelalação da teoria com a prática;

- Incentivar a participação dos discentes em projetos de extensão, cujas horas serão passíveis de compor a carga horária do curso.

Segundo a autora, com as DCN, não mais se objetiva formar um profissional "preparado", mas sim adaptável às constantes mudanças do mundo. Isso será 
possível com a flexibilização dos projetos pedagógicos, pois cada Instituição poderá e deverá adaptá-lo às constantes e velozes mudanças de nosso tempo.

\section{Recomendações da DCN para a elaboração dos projetos pedagógicos}

Segundo o parágrafo 1 do segundo artigo da Resolução CNE/CES5/2004 de 8 de março de 2004, deverão ser definidos os princípios que servem de base para a concepção do curso, assim como o currículo e os mecanismos para o seu fluxo efetivo, e uma coesiva forma de avaliação.

Os seguintes elementos são fundamentais:

"I - objetivos gerais do curso, contextualizados em relação às outras inserções, institucional, política, geográfica e social;

II - condições objetivas de oferta e vocação do curso;

III - cargas horárias das atividades didáticas e da integralização do curso;

IV - formas de realização das interdisciplinaridades;

V - modos de integração entre teoria e prática;

VI - formas de avaliação do ensino e da aprendizagem;

VII - modos de integração entre graduação e pósgraduação, quando houver;

VIII - cursos de pós-graduação lato sensu, nas modalidades especialização integrada e/ou subsequente à graduação, de acordo com o surgimento das diferentes manifestações teórico-práticas, e tecnológicas aplicadas à área da graduação, e de aperfeiçoamento, de acordo com as efetivas demandas do desempenho profissional;

IX - incentivo à pesquisa, como necessário prolongamento da atividade de ensino e como instrumento para a iniciação científica.

X - concepção e composição das atividades de estágio 
curricular supervisionado, suas diferentes formas e condições de realização, observado o respectivo regulamento;

XI - concepção e composição das atividades complementares;

XII - inclusão opcional de trabalho de conclusão de curso sob as modalidades: projeto de iniciação científica, projetos de atividades centrados em áreas teórico-práticos ou de formação profissional, na forma como estabelecer o regulamento próprio. (CNE/CES, 2004, p. 1)

Sobre a prática de disciplinas de projeto, Fontoura (2002, p. 34) relata:

...o andamento de um projeto sempre se difere de outros com a mesma natureza. As abordagens ao problema são sempre diferentes e estão sujeitas às concepções, aos entendimentos, conhecimentos, experiências do designer e à orientação dada por ele ou pela equipe de projeto. Elas servem apenas como orientações, jamais como caminhos fixos e invariáveis. O Design é, na maior parte das vezes, avaliado - e classificado - pelos seus resultados e não pelo caminho adotado por ele.

\section{O curso}

O curso de bacharelado em Design Gráfico da Universidade Estadual de Londrina (UEL) teve seu início no ano de 1997, sendo reconhecido no ano de 2003 (Decreto Estadual n.ำ1728). Após seu reconhecimento já ocorreram duas reformulações, visando sempre atender as inovações do mercado. Em 2014, o curso completa 18 anos. Este tem duração mínima de quatro e máxima de oito anos, e as aulas são realizadas no período matutino. O sistema acadêmico é do tipo seriado anual, recebendo a cada ano vinte novos alunos.

Na avaliação no Ministério da Educação e Cultura, o curso conta atualmente com a nota 4, tendo um bom conceito junto à universidade e sociedade em geral, sendo reconhecido em nível regional. É atualmente o quinto curso de graduação da UEL mais procurado pelos vestibulandos, com média de candidato/vaga de 22 (sistema universal) e 21,5 (cotas de escola pública) no processo seletivo de 2013. A carga horária atual é de 3.263 horas, das quais 1.700 de atividades teóricas, 1.326 de atividades práticas, 102 de estágio obrigatório e 135 de atividades complementares. 
O currículo atual do curso foi implantado em 2005 e reformulado em 2010, mas mantém quase a mesma estrutura com base em grade de disciplinas. Tendo como base as discussões realizadas a partir do segundo semestre de 2013, o grupo docente considera que essa estrutura já não é mais adequada ao contexto social, econômico e tecnológico atual.

\section{O contexto}

Fatores significativos como o crescimento econômico do país, com conseqüente aumento do poder econômico da população, principalmente da classe média, e o surgimento de políticas públicas de inclusão social foram determinantes para as mudanças no perfil dos cursos de design em nível nacional, nos últimos anos.

O sistema de cotas para entrada nas universidades públicas, por exemplo, provocou uma mudança significativa no perfil dos ingressantes ao curso, sendo que em 2013 os alunos cotistas representaram 40\% dos novos alunos ingressantes no curso de Design Gráfico da UEL, a maioria vinda de escolas públicas, segundo dados da Pró-Reitoria de Graduação da UEL (PROGRAD).

Além disso, o momento econômico favorável que o país atravessa, fruto em grande parte da existência de um mercado interno forte e de uma relativa estabilidade econômica, favorece a inserção dos formandos em design gráfico no mercado, seja como empregados em empresas ou como novos empreendedores de negócios próprios em design. Nesse sentido, de forma geral os egressos do curso não têm encontrado grandes dificuldades para inserir-se no mercado nos últimos anos.

A internacionalização é outro fator relevante, com um aumento significativo na quantidade de alunos do curso que tem realizado intercâmbios internacionais, e compartilhado suas experiências no curso ao retornar; os alvos preferenciais têm sido o Canadá, Estados Unidos, México, Inglaterra e Irlanda. Por outro lado, a recepção a alunos vindos de outros países, especialmente da África, tem contribuído recentemente para enriquecer culturalmente o ambiente do curso.

O contexto tecnológico também é um grande influenciador no modo como o curso deverá se estruturar nos próximos anos. O aumento no uso de tablets e smartphones, o uso de softwares que funcionam totalmente online, e novas tecnologias de criação e prototipagem como a modelagem 3 d, impressão $3 \mathrm{~d}$ e digitalização $3 \mathrm{~d}$ cada vez melhores e mais acessíveis são apenas alguns dos novos fatores que deverão provocar grandes mudanças na forma como se ensina e se aprende design, e o currículo do curso deverá se adequar a essa 
nova realidade.

Essa adequação é fundamental ao se verificar o objetivo geral colocado no Projeto Pedagógico do curso de Design Gráfico da UEL, que é "Oferecer a formação em Design Gráfico, visando desenvolver a capacidade analítica, crítica e expressiva, integrada à realidade contemporânea".

A realidade contemporânea é, neste sentido, muito mais complexa e dinâmica do que aquela de quando o curso foi criado em 1997. Neste novo contexto é que se insere o desafio de reestruturação do curso de Design Gráfico da UEL, e que exige a elaboração e busca de respostas para algumas questões fundamentais, tendo o aluno como ponto de partida.

A partir do aprendizado durante o evento da Jornada Pedagógico, conduzido pela profa Dra Lea Anastasiou na UEL, em 2013, e voltado às coordenações de cursos de graduação, as discussões sobre o novo projeto pedagógico e respectivo currículo foram iniciadas a partir de três questões principais:

- Que perfil de curso queremos?

- Que perfil de aluno queremos formar?

- Que perfil de aluno temos?

Não são questões triviais, pois exigem do grupo de docentes uma análise aprofundada da realidade atual e das possibilidades futuras para o curso, considerando um contexto social, econômico e tecnológico amplo e complexo.

\section{O currículo atual}

O currículo atual do curso de Design Gráfico da UEL é estruturado com base em uma grade de disciplinas, as quais são distribuídas em séries letivas

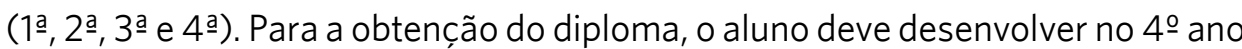
um Trabalho de Conclusão de Curso (TCC), realizar o Estágio Obrigatório em uma empresa ligada à área de design, e integralizar um mínimo de atividades complementares. Estas atividades podem ser disciplinas especiais ou eletivas, projetos de pesquisa, ensino ou extensão, estágio não obrigatório, eventos e outros cursos, e monitoria em alguma disciplina.

Quanto ao tema da interdisciplinaridade, para Fontoura (2002, p. 52), os benefícios de sua aplicação no ensino são evidentes. Porém, alguns aspectos dificultam a sua implementação, como

...estruturas administrativas e acadêmicas lentas,
preconceitos, falta de autonomia, falta de preparo


e insegurança dos educadores, que geralmente transformam-se em verdadeiras barreiras para qualquer iniciativa diferente das triviais. Estes fatores são obstáculos de origem epistemológica, institucional, psico-sociológica e cultural.

Os alunos executam vários projetos ao longo do curso a fim de desenvolverem sua capacidade projetual, os quais são propostos pelos professores de modo crescente em termos de complexidade. No entanto, há várias fragilidades no modelo curricular atual, sendo as principais:

- Falta de articulação mais efetiva das disciplinas para atividades interdisciplinares;

- Falta de um melhor planejamento das atividades práticas, implicando freqüentemente em excesso de atividades concomitantes para os alunos, que acabam por priorizar alguns trabalhos em detrimento de outros;

- Dificuldade de abordagem didática adequada ao design em algumas disciplinas, em especial quando são dadas por outros departamentos;

- Falta de envolvimento de professores de outros departamentos no planejamento didático-pedagógico do curso;

- Existência de disciplinas defasadas em relação ao conteúdo e, em alguns casos, à importância real para o curso.

Estas fragilidades estão ligadas também a outras dificuldades enfrentadas pelo curso, entre elas:

- Falta de investimento público adequado para os laboratórios e outros espaços de trabalho do departamento;

- Quantidade significativa de professores em capacitação em nível de doutorado no momento (metade do grupo), com dificuldade de conciliar as atividades de ensino, pesquisa e extensão com as de capacitação. Esta situação é ainda agravada pela impossibilidade de concessão de licença de forma adequada para os professores se dedicarem à capacitação;

- Dificuldade de acompanhar as freqüentes necessidades de atualização tecnológica do curso, seja de computadores e outros equipamentos ou de softwares gráficos adequados; 
- Excesso de procedimentos burocráticos que ocupam tempo dos professores em atividades que não agregam valor para o ensino, extensão e pesquisa, e que dificultam muitas vezes o acesso adequado aos recursos.

Apesar disso, o curso tem conseguido manter um padrão de qualidade no ensino, o que pode ser visto, por exemplo, na qualidade dos projetos desenvolvidos ao longo do mesmo e na boa colocação no mercado pelos egressos. Esta qualidade é fruto, por um lado, da dedicação, experiência teóricometodológica e conceitual e criatividade dos professores.

Por outro lado, a dedicação, criatividade e capacidade de solução de problemas dos alunos são significativas, buscando superar as dificuldades estruturais do curso para produzir trabalhos de qualidade.

Apesar dessa dedicação de ambos os lados, tanto docentes quanto discentes concordam que o modelo didático-pedagógico praticado não é mais suficiente para dar conta das necessidades atuais, e por este fato foi iniciado em 2013 o processo de reforma do projeto pedagógico, incluindo a construção de um novo modelo curricular.

\section{O processo de reforma do projeto pedagógico e do currículo}

O fator desencadeador do processo de reforma do projeto pedagógico e currículo foi a realização do evento Jornada Pedagógica, que ocorreu na UEL em 2013, e foi coordenado pela profa Dra Lea Anastasiou, conforme já citado anteriormente. Neste evento, do qual participou a coordenação do curso de Design Gráfico e de vários outros cursos da UEL, foram discutidos pontos como:

- Renovação da motivação da coordenação;

- Ampliação da percepção dos problemas comuns às coordenações;

- Ampliação da percepção da importância da avaliação no curso e na universidade;

- Ampliação da percepção da importância da alta responsabilidade na gestão do curso;

- Ampliação da percepção da importância do Núcleo Docente estruturante;

- Autoanálise da gestão na coordenação; 
- Avaliação do projeto pedagógico do curso;

- Levantamento de dados do curso sob o ponto de vista pedagógico, bem como das condições concretas de trabalho e a qualidade de ensino e aprendizagem;

- Levantamento das disciplinas e suas inter-relações;

- Analise de dados trazidos pelos estudantes (pedagógicos, administrativos e outros);

- Identificação das linhas mestras e orientadoras dos saberes do curso, ou possíveis eixos articuladores;

- Levantamento e análise de determinantes chaves da questão curricular (conceito de currículo, de articulação, de determinação legal, de fragmentação e complexidade, de pensamento complexo, do cérebro e seu funcionamento, dos desafios relacionais entre interpessoais).

Estas discussões foram fundamentais para que a reforma do projeto pedagógico pudesse ser iniciada, e culminou com a criação de um grupo de trabalho formado por docentes do curso de Design Gráfico, que trabalhou a partir destes e outros pontos. As atividades deste grupo incluíram:

- A preparação, a partir dos pontos trabalhados na Jornada Pedagógica;

- A busca de documentação de apoio;

- A pesquisa por iniciativas similares;

- A elaboração da nova proposta curricular;

- A submissão da nova proposta para apreciação pelos alunos e por docentes de outras instituições.

\section{Documentação de apoio}

Para subsidiar as discussões do novo projeto pedagógico foram utilizados os seguintes documentos:

- Lei de Diretrizes e Bases da Educação, Lei no 9394, de 20/12/96; 
- Resolução no 5, de 08/03/2004, sobre as diretrizes curriculares do Curso de Graduação em Design;

- Projeto pedagógico atual do curso de Design Gráfico da UEL (antigo PPP);

- Resolução CU no 313/2005, sobre o Regimento do Colegiado do Curso de Design Gráfico;

- Resolução CEPE no 0249/2009, que reformula o Projeto Pedagógico do Curso de Design Gráfico a partir de 2010;

- Anexo da Resolução CEPE no 0249/2009, com os conteúdos curriculares, eixos de conhecimento, ementas das disciplinas e respectivas cargas horárias a partir de 2010;

- Deliberação Câmara de Graduação no 019/2010, sobre carga horária de Atividades Acadêmicas Complementares a partir de 2010;

- Atribuições do coordenador de colegiado e PP do curso, fornecido pela própria universidade;

- Tabela de especificidade de carga horária por professor em 2012;

- Ato executivo no 63/2011, sobre o Regimento Eleitoral para eleição de Coordenadores e Vice Coordenadores de Colegiados de Cursos de Graduação da UEL;

- Instrumento de Avaliação de Cursos de Graduação presencial e à distância, do MEC, de 2012;

- Portaria Normativa no 40, de 12/12/2007, sobre o e-MEC, e indicadores de qualidade, banco de avaliadores e ENADE;

- Perfil dos ingressantes na UEL em 2013, fornecido pela universidade (40\% dos alunos são oriundos do sistema de cotas, sendo 06 de escola pública e 02 de cor);

- Estruturas curriculares de outros cursos com modelos distintos;

- Arquivos de documentos diversos do curso, fornecidos em CD pela equipe da PROGRAD durante a Jornada Pedagógica; 
- Leituras adicionais, como o livro "Escritos sobre Ensino de Design no Brasil" de Rita Maria de Souza Couto.

\section{A definição das diretrizes para o novo curso}

Após o levantamento e análise dos diversos documentos que subsidiaram as discussões, foram definidas pelo grupo as seguintes diretrizes que deveriam nortear o novo projeto pedagógico:

- Maior ênfase na prática reflexiva, com valorização das atividades de projeto;

- Maior articulação interdisciplinar, tendo os projetos como elementos estruturadores dos conteúdos a serem trabalhados;

- Ênfase na qualidade em vez da quantidade de trabalhos a serem realizados pelos alunos;

- Ênfase no desenvolvimento de competências em vez de conteúdos, evidenciando as competências que já estão presentes no projeto pedagógico atual, como a capacidade criativa e inovadora, linguagem própria, interação interdisciplinar, visão sistêmica de projeto, domínio das etapas de projeto, conhecimento do setor produtivo e visão histórica e prospectiva;

- Definição mais clara dos eixos norteadores do curso, tendo como base as competências citadas anteriormente;

- Inserção de novos conteúdos que estejam em sintonia com a realidade atual e as tendências sociais, culturais, econômicas e tecnológicas previstas para os próximos anos;

- Retirada de conteúdos que não sejam mais necessários;

- Inserção das questões socioeconômicas (ex.: inclusividade, valorização cultural, qualidade de vida, hábitos de consumo, empreendedorismo) e ambientais (ex.: uso de recursos naturais, ocupação do território, descarte e tratamento de resíduos) relevantes atualmente e para o futuro próximo.

\section{A busca de iniciativas similares}

Nesta etapa foram identificados currículos de cursos que pudessem servir 
de referência para a elaboração do novo curso. Entre os que foram estudados estão:

- Curso de Tecnologia em Design de Produto do CEFET/SC (atualmente IFSC);

- Curso de Design Gráfico da Universidade Positivo/PR;

- Curso de Design da Universidade Federal do Paraná.

\section{A elaboração da nova proposta curricular}

A partir do levantamento dos possíveis regimes acadêmicos para o novo projeto pedagógico previstos na Resolução no 5, de 08/03/2004 (diretrizes curriculares do Curso de Graduação em Design), verificou-se que são possíveis quatro modalidades:

- Seriado anual (praticado atualmente no curso de Design Gráfico da UEL);

- Seriado semestral;

- Créditos com matrícula por disciplina;

- Módulos acadêmicos (praticado pelo curso de Tecnologia em Design de Produto do IFSC, antigo CEFET/SC).

Considerando então as diretrizes colocadas anteriormente, e as possíveis modalidades curriculares, foi elaborada a primeira proposta para o novo currículo, tendo como base o sistema por módulos acadêmicos, os quais seriam operacionalizados na forma de projetos. Cada um destes módulos teria um tema específico a ser desenvolvido semestralmente, acompanhado dos respectivos conteúdos-chave, conforme o Figura 1:

Figura 01 - Proposta inicial de currículo por módulos de projeto. 


\begin{tabular}{|c|c|c|}
\hline & 10 semestre & 20 semestre \\
\hline Ano 1 & $\begin{array}{l}\text { Fundamentos I (320h) } \\
\text { Teóricos } \\
\text { História da Arte e das Técnicas } \\
\text { Fundamentos do Design } \\
\text { Criatividade } \\
\text { Antropologia e Cultura } \\
\text { Teórico-práticos } \\
\text { Desenho de Observação e Expressão } \\
\text { Redação e Expressão Oral } \\
\text { Metodologia de Pesquisa Científica }\end{array}$ & $\begin{array}{l}\text { Fundamentos II (320h) } \\
\text { Teóricos } \\
\text { Teoria da Percepção } \\
\text { Sintaxe Visual } \\
\text { Teoria e Prática da Cor } \\
\text { Psicologia Aplicada ao Design } \\
\text { Teórico-práticos } \\
\text { Fotografia } \\
\text { Representaãão Bi e Tridimensional } \\
\text { Computaçăo Gráfica } \\
\text { Metodologia de Pesquisa em Design }\end{array}$ \\
\hline Ano 2 & $\begin{array}{l}\text { Projeto I (320h) } \\
\text { Ilustração | HQ | Animação | Objetos }\end{array}$ & $\begin{array}{l}\text { Projeto II (320h) } \\
\text { Editorial | Web | Interface Digital }\end{array}$ \\
\hline Ano 3 & $\begin{array}{l}\text { Projeto III (320h) } \\
\text { Identidade | Design Gráfico Ambiental }\end{array}$ & $\begin{array}{l}\text { Projeto IV ( } 320 \mathrm{~h}) \\
\text { Design de superfície | Embalagem | Objetos }\end{array}$ \\
\hline Ano 4 & $\begin{array}{l}\text { Projeto V (320h) } \\
\text { Gestão Estratégica de Design }\end{array}$ & $\begin{array}{l}\text { TCC e Estágio (320h) } \\
\text { TCC | Estágio Obrigatório }\end{array}$ \\
\hline
\end{tabular}

Fonte: Elaborado pelos autores.

Neste primeiro modelo os conteúdos não seriam mais trabalhados na forma de disciplinas, mas sim de um projeto principal, que seria alimentado por grupos de apoio, os quais seriam organizados na forma de grupos por competências teóricas e teórico-práticas. Neste caso, as aulas em sala de aula seriam substituídas por grupos de estudo em cada tema, com o objetivo de buscar o conteúdo necessário para desenvolver o projeto em foco naquele momento. Trata-se, portanto, de uma mudança radical em relação ao modelo de grade curricular atualmente utilizado no curso.

Posteriormente, essa primeira proposta foi discutida exaustivamente pelo grupo, e no mês de Abril de 2014 foi elaborado um segundo modelo, que mantém os projetos como elementos norteadores do currículo, mas que também prevê que os conteúdos a serem trabalhados nos projetos sejam estruturados na forma de disciplinas. Percebe-se que, neste caso, trata-se de um modelo intermediário entre o anterior e o atualmente praticado no curso. Este modelo é apresentado no Quadro 1, e baseia-se em uma matriz que organiza as disciplinas em torno de quatro eixos fundamentais.

1.

Quadro 01 - Segunda proposta para o novo currículo, combinando a abordagem por projetos com os conteúdos de apoio na forma de disciplinas.

\begin{tabular}{|c|c|c|c|c|}
\hline & $\begin{array}{l}\text { FUNDAMEN- } \\
\text { TAC̣ÃO }\end{array}$ & $\begin{array}{l}\text { REPRESEN- } \\
\text { TAÇÃO E } \\
\text { EXPRESSÃO }\end{array}$ & $\begin{array}{l}\text { SISTEMA DE } \\
\text { PRODUCCÃO E } \\
\text { UTILIZAC̣ÃO }\end{array}$ & $\begin{array}{l}\text { GESTÃO E } \\
\text { PROJETO }\end{array}$ \\
\hline $\begin{array}{l}\text { 10 ANO } \\
\text { (Projeto de } \\
\text { Design de } \\
\text { Superfície) }\end{array}$ & $\begin{array}{l}\text { História da } \\
\text { Arte I } \\
\text { Teoria e Prática } \\
\text { da Cor } \\
\text { Sintaxe Visual I }\end{array}$ & $\begin{array}{l}\text { Desenho de } \\
\text { Observação } \\
\text { Fotografia } \\
\text { Técnicas Dig- } \\
\text { itais I } \\
\text { Ilustração I }\end{array}$ & & \\
\hline
\end{tabular}




\begin{tabular}{|c|c|c|c|c|}
\hline & $\begin{array}{l}\text { Fundamentos } \\
\text { do Design } \\
\text { História da } \\
\text { Arte II } \\
\text { Sintaxe Visual II }\end{array}$ & $\begin{array}{l}\text { Técnicas Digi- } \\
\text { tais II } \\
\text { Plástica } \\
\text { Desenho } \\
\text { Geométrico } \\
\text { Ilustração II } \\
\text { Design Fo- } \\
\text { tográfico }\end{array}$ & $\begin{array}{l}\text { Produção } \\
\text { Gráfica I }\end{array}$ & $\begin{array}{l}\text { Design de } \\
\text { Superfície }\end{array}$ \\
\hline \multirow[t]{2}{*}{$\begin{array}{l}\text { 20 ANO } \\
\text { (Projeto } \\
\text { de Design } \\
\text { Instrucio- } \\
\text { nal) }\end{array}$} & $\begin{array}{l}\text { Teoria da Co- } \\
\text { municação } \\
\text { Teoria da Per- } \\
\text { cepção } \\
\text { Processo de } \\
\text { Design }\end{array}$ & $\begin{array}{l}\text { H.Q. } \\
\text { Técnicas Digi- } \\
\text { tais III } \\
\text { Pré-Produção }\end{array}$ & $\begin{array}{l}\text { Produção } \\
\text { Gráfica II } \\
\text { Ergonomia } \\
\text { Visual I }\end{array}$ & $\begin{array}{l}\text { Design In- } \\
\text { stitucional } \\
\text { (identidade } \\
\text { e suas man- } \\
\text { ifestações) }\end{array}$ \\
\hline & $\begin{array}{l}\text { Semiótica I } \\
\text { Midiologia } \\
\text { Antropologia } \\
\text { Visual } \\
\text { Metodologia } \\
\text { da Pesquisa } \\
\text { Científica }\end{array}$ & $\begin{array}{l}\text { Tipografia I } \\
\text { Design em } \\
\text { Movimento I } \\
\text { Modelagem e } \\
\text { Renderização } \\
\text { 3D I }\end{array}$ & $\begin{array}{l}\text { Ergonomia } \\
\text { Visual II } \\
\text { Design da } \\
\text { Informação } \\
\text { I (Infogra- } \\
\text { fia) }\end{array}$ & $\begin{array}{l}\text { Wayfinding } \\
\text { e Sinal- } \\
\text { ização }\end{array}$ \\
\hline \multirow{2}{*}{$\begin{array}{l}\text { 30 ANO } \\
\text { (Projeto de } \\
\text { Design In- } \\
\text { stitucional } \\
\text { e Editorial } \\
\text { e embala- } \\
\text { gem) }\end{array}$} & $\begin{array}{l}\text { Semiótica II } \\
\text { (Peirce) } \\
\text { Design e Suste- } \\
\text { ntabilidade } \\
\text { Psicologia do } \\
\text { Usuário }\end{array}$ & $\begin{array}{l}\text { Planejamento } \\
\text { Visual I } \\
\text { Tipografia II } \\
\text { Design em } \\
\text { Movimento II }\end{array}$ & $\begin{array}{l}\text { Interface } \\
\text { Digital I } \\
\text { (IHC) } \\
\text { Embala- } \\
\text { gem I }\end{array}$ & $\begin{array}{l}\text { Projeto } \\
\text { Vestibular } \\
\text { Branding e } \\
\text { Comuni- } \\
\text { cação }\end{array}$ \\
\hline & $\begin{array}{l}\text { Prod. e Análise } \\
\text { da Imagem } \\
\text { Estética } \\
\text { Design e Cul- } \\
\text { tura } \\
\text { Direito Autoral }\end{array}$ & $\begin{array}{l}\text { Vídeo } \\
\text { Modelagem e } \\
\text { Renderização } \\
\text { 3D II }\end{array}$ & $\begin{array}{l}\text { Interface } \\
\text { Digital II } \\
\text { Embalagem } \\
\text { II }\end{array}$ & $\begin{array}{l}\text { Design } \\
\text { Editorial }\end{array}$ \\
\hline \multirow[t]{2}{*}{$\begin{array}{l}\text { 4 ANO } \\
\text { (Projeto de } \\
\text { Design Pro- } \\
\text { mocional) }\end{array}$} & $\begin{array}{l}\text { Inovação e } \\
\text { Tendências }\end{array}$ & & $\begin{array}{l}\text { Interface } \\
\text { Digital II } \\
\text { (Mídias } \\
\text { Móveis) }\end{array}$ & $\begin{array}{l}\text { Design Pro- } \\
\text { mocional } \\
\text { Empreende- } \\
\text { dorismo } \\
\text { Gestão de } \\
\text { Design } \\
\text { Estágio } \\
\text { TCC } \\
\text { Seminários } \\
\text { de Projeto }\end{array}$ \\
\hline & & & & $\begin{array}{l}\text { Estágio } \\
\text { TCC } \\
\text { Seminários } \\
\text { de Projeto }\end{array}$ \\
\hline
\end{tabular}

Fonte: Autores 


\section{A submissão da nova proposta para apreciação pelos alunos e por docentes de outras instituições}

Uma vez que os dois modelos propostos foram discutidos intensamente, o grupo entende que, a partir de agora, torna-se relevante identificar a percepção dos alunos e de profissionais já formados na área quanto às propostas, e também de professores de outras instituições que já tenham passado por processos semelhantes. Esta contribuição será valiosa para o sucesso desta mudança, e este é o principal objetivo da participação do curso de Design Gráfico no evento Fórum de Ensino em Design da UEL, a ser realizado neste ano: compartilhar, ouvir, dialogar e aprender com o intuito de aprimorar o modelo proposto, ou mesmo reformulá-lo.

\section{REFERÊNCIAS}

BRASIL. Senado Federal. Lei de Diretrizes e Bases da Educação Nacional: no 9394/96. Brasília: 1996. Disponível em: <http://www.planalto.gov. br/ccivil_03/leis/I9394.htm> Acesso em: 10 ago. 2013.

\section{CONSELHO NACIONAL DE EDUCAÇÃO - CNE/CÂMARA DE} EDUCAÇÃO SUPERIOR - CES. Resolução no 5, de 8 de março de 2004. Brasília: 2004. Disponível em: <http://portal.mec.gov.br/cne/arquivos/ pdf/rces05_04.pdf>. Acesso em: 10 ago. 2013.

COUTO, R. M. de S. Escritos sobre Ensino de Design no Brasil. Rio Books. Rio de Janeiro: 2008.

FONTOURA, Antonio M. EdaDe. Educação de crianças e jovens através do design. Florianópolis, 2002. 337p. Tese (Doutorado em Engenharia da Produção) - Programa de Pós-graduação em Engenharia de Produção, Santa Catarina: UFSC, 2002.

MINISTÉRIO DA EDUCAÇÃO. Instrumento de Avaliação de Cursos de Graduação presencial e à distância, do MEC, de 2012; Disponível em: <http://www.abmes.org.br/abmes/documentos/visualizar/id/157> Acesso em: 10 ago. 2013.

MINISTÉRIO DA EDUCAÇÃO. Portaria Normativa no 40, de 12/12/2007, sobre o e-MEC, e indicadores de qualidade, banco de avaliadores e ENADE. Disponível em: <http://meclegis.mec.gov.br/documento/view/id/17> Acesso em: 10 ago. 2013. 
Resolução CEPE no 0249/2009, com os conteúdos curriculares, eixos de conhecimento, ementas das disciplinas e respectivas cargas horárias a partir de 2010. Londrina: 2009. Disponível em: <http://www.uel.br/prograd/ pp/documentos/2010/resolucao_249_09.pdf> Acesso em: 10 ago. 2013.

UNIVERSIDADE ESTADUAL DE LONDRINA - UEL. Ato executivo $n^{\circ}$ 63/2011, sobre o Regimento Eleitoral para eleição de Coordenadores e Vice Coordenadores de Colegiados de Cursos de Graduação da UEL. Disponível em: <http://www.uel.br/com/agenciaueldenoticias/fotos/13-10-2011g-ato63.PDF> Acesso em: 10 ago. 2013.

UNIVERSIDADE ESTADUAL DE LONDRINA - UEL. Atribuições do coordenador de colegiado e PP do curso. Disponível em: <http://www. uel.br/prograd/camara_graduacao/apresentacao_prograd/02_ atribuicoes_coordenadores_colegiado_pp.pdf> Acesso em: 10 ago. 2013.

UNIVERSIDADE ESTADUAL DE LONDRINA - UEL. Deliberação Câmara de Graduação no 019/2010, sobre carga horária de Atividades Acadêmicas Complementares a partir de 2010. Londrina: 2009. Disponível em: <http://www.uel.br/prograd/docs_prograd/deliberacoes/ deliberacao_19_10.pdf> Acesso em: 10 ago. 2013.

UNIVERSIDADE ESTADUAL DE LONDRINA - UEL. Perfil do Ingressante - Vestibular 2013 Geral da UEL. Disponível em: <http://www.uel.br/ proplan/aval-institucional/Ingressante_Geral_2013.pdf> Acesso em: 10 ago. 2013.

UNIVERSIDADE ESTADUAL DE LONDRINA - UEL. Resolução CEPE no 0249/2009, que reformula o Projeto Pedagógico do Curso de Design Gráfico a partir de 2010. Londrina: 2009. Disponível em: <http://www. uel.br/prograd/pp/documentos/2010/resolucao_249_09.pdf> Acesso em: 10 ago. 2013.

UNIVERSIDADE ESTADUAL DE LONDRINA - UEL. Resolução CU no 313/2005, sobre o Regimento do Colegiado do Curso de Design Gráfico. Londrina: 2005. 